\title{
Gradhiva
}

\section{Pierre Richard (1802-1879), Grimoires illuminés}

Paris, Artulis/Pierrette Turlais, 2019

\section{Baptiste Brun}

\section{OpenEdition}

\section{Journals}

Édition électronique

URL : https://journals.openedition.org/gradhiva/5838

DOI : $10.4000 /$ gradhiva.5838

ISSN : 1760-849X

Éditeur

Musée du quai Branly Jacques Chirac

\section{Édition imprimée}

Date de publication : 24 mars 2021

Pagination : 229-230

ISBN : 978-2-35744-132-3

ISSN : 0764-8928

Référence électronique

Baptiste Brun, «Pierre Richard (1802-1879), Grimoires illuminés », Gradhiva [En ligne], 32 | 2021, mis en ligne le 02 avril 2021, consulté le 25 mai 2021. URL : http://journals.openedition.org/gradhiva/5838 ; DOI : https://doi.org/10.4000/gradhiva.5838

Ce document a été généré automatiquement le 25 mai 2021

(c) musée du quai Branly 


\section{Pierre Richard (1802-1879), Grimoires}

\section{illuminés}

Paris, Artulis/Pierrette Turlais, 2019

Baptiste Brun

\section{RÉFÉRENCE}

Pierre Richard (1802-1879), Grimoires illuminés. Paris, Artulis/Pierrette Turlais, 2019, 280 p. www.editionsartulis.fr

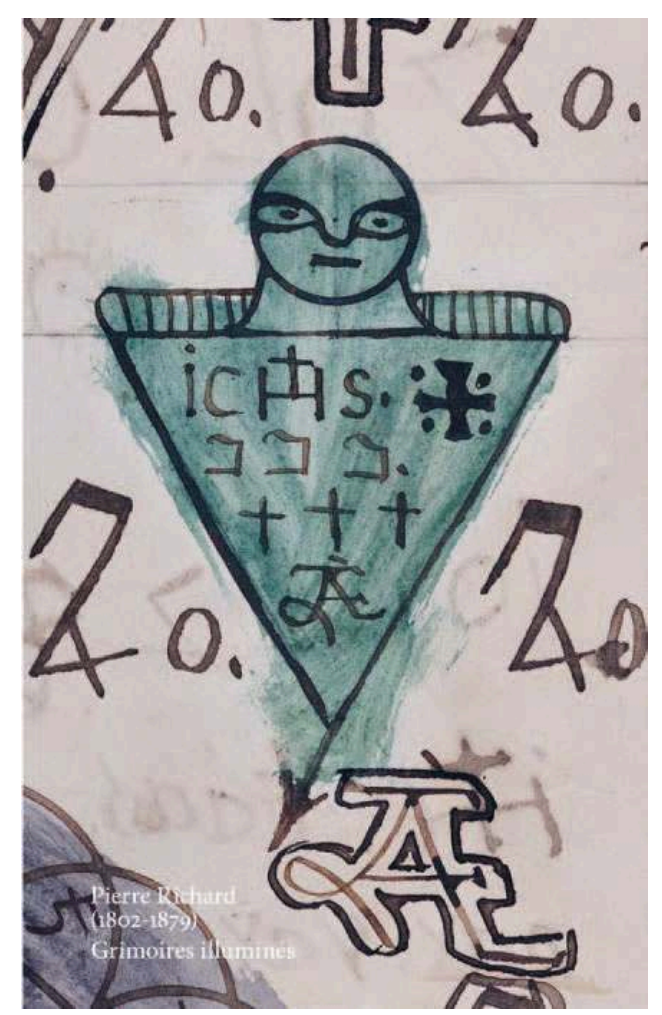


1 Découverts en 2010 sur le marché du livre, les manuscrits enluminés de Pierre Richard ont été très rapidement considérés comme des objets majeurs apparentés à l'art brut. La publication merveilleusement éditée par Pierrette Turlais, la grande qualité de son élaboration et de sa fabrique tiennent évidemment une grande part dans cette reconnaissance quasi immédiate. Mais cette affiliation repose avant tout et sans conteste sur le caractère insolite des graphies et dessins saturant les pages de l'imprimé et des deux albums qui, à ce jour, constituent l'ouvrage de Pierre Richard. Né à Kédange (Moselle) en 1802, ce paysan et propriétaire lorrain est mort en 1879 non loin de là, à Gorze près de Metz, fort probablement dans l'asile d'aliénés où il avait été placé neuf ans auparavant. Peut-être la dépossession de ses biens par son demi-frère suite à la disparition de sa mère explique-t-elle une progressive perte du lien social qui conduit malheureusement l'homme à l'internement. C'est du moins ce que peuvent laisser à penser les très rares archives qui permettent de situer l'auteur, exhumées par les historiens François et Mireille Pétry, principaux artisans de cette découverte. Recoupant quelques actes de l'état civil avec de menues informations redondantes glanées lors du relevé scrupuleux et quasi maniaque des inscriptions et figures de ce qu'ils ont appelé les trois " grimoires ", les deux chercheurs ont émis de nombreuses hypothèses quant à la vie et à la production graphique de Pierre Richard. Servis par une érudition conséquente, leurs travaux sont enrichis des contributions des historiens Nicolas Weill-Parot et Jean-Pierre Brach, des historiens de l'art Marc Décimo et Christophe Boulanger, et de la psychanalyste Lise Maurer. Une préface de l'artiste Annette Messager consacre l'artification de l'« œuvre ».

2 Le terme même de "grimoire " adopté pour qualifier le singulier ouvrage de Pierre Richard est justifié par l'appropriation d'un imprimé, l'Enchiridion du pape Léon, une publication présente encore aujourd'hui au rayon ésotérisme des librairies. Daté de 1800 , ce recueil d'oraisons, de psaumes, de formules et schèmes de tradition occulte prétendument adressé à Charlemagne par le pape Léon III au IX siècle est dédié « aux sages cabalistes ». Le goût populaire pour l'occultisme véhiculé par la littérature de colportage trouve là un émissaire exemplaire. Ce petit livre regorge de formules supposées magiques qui s'entremêlent à des contenus chrétiens, des signes hébraïques, des pentacles et autres carrés magiques qui forment la matrice d'autres formules et figures que démultiplie Pierre Richard à l'intérieur et autour de l'ouvrage. En effet, ce dernier a "augmenté " son exemplaire de l'Enchiridion de ses annotations et de cent vingt pages supplémentaires saturées de graphies diverses. C'est à proprement parler un livre d'usage qu'il active pour se protéger, conjurer ses ennemis, gagner son salut. L'écriture suggère, par les redondances, variations et inventions des signes qu'elle trace, qu'elle est investie d'une valeur opératoire à proprement parler magique. La ferveur le dispute au délire, la psalmodie à la glossolalie, la lettre au signe cryptique. Si l'on suit l'hypothèse de datation des Pétry, les deux albums qui s'ajoutent à l'Enchirdion creusent le sillon qu'il esquisse. De format plus conséquent, ils en reprennent les inventions en multipliant les variations. À parcourir les pages du livre où les reproductions en fac-similé donnent à voir l'exubérance mais aussi la forme de cohérence propre à la manie de Pierre Richard, on constate comme un surinvestissement d'énergie dans l'écriture que l'horreur du vide amplifie.

3 La partie plus graphique et figurative n'est pas en reste, prenant pour motif de prédilection la Passion du Christ. Arma Christi, crucifixion, voile de Véronique et cohortes d'anges armés reprennent assez rigoureusement les codes iconographiques 
des cultures savante et populaire mais d'une manière toute singulière. Les écarts et inventions sont d'autant plus savoureux : une Vierge à l'enfant portant sabre ou un coq armé d'un pistolet perché sur la croix. Ce dernier motif évoquant le reniement de Pierre a sans doute quelque chose d'autobiographique. Enfin, il y a les motifs qui ne sont ni figures ni écritures à proprement parler, monogrammes multiples qui sont tout à la fois le nom de Dieu et celui de l'auteur. La fusion est parfois complète. Pierre est Dieu en somme. Tout renvoie à la pulsion de faire signe chez un homme de peu de lettres, au-delà de la sémantique, renforçant la dimension cryptique qui auréole d'une couche de mystère supplémentaire ces scriptions en prise avec la magie ${ }^{1}$.

Comme l'écrit l'historien Nicolas Weill-Parot, la magie de Pierre Richard et l'usage qu'il en fait relèvent d'une "magie solipsiste» (p. 71). Ce dernier qualifie d'ailleurs les grimoires du Lorrain d'" héritiers inconscients et déviants» de la "magie rituelle, d'origine essentiellement judéo-chrétienne (beaucoup plus rarement musulmane) et fondée sur l'invocation de démons contraints avec l'aide divine ou sur l'appel à des anges suppliés humblement ", les mêmes qui jalonnent les pages de Pierre Richard et soutiennent ses supplications. À l'évidence et heureusement, la prudence de l'exégète est de mise. Souvent, les artefacts qui s'apparentent à l'art brut et leur interprétation inspirent maintes hypothèses plus ou moins solides que la position autistique ou du moins asociale de ceux qui les fabriquent permet rarement de vérifier. L'art brut a quelque chose d'analogue à l'art paléolithique: le silence qu'il oppose à celui qui l'interroge. Et s'il existe un "syncrétisme richardien» (p.152) qui entremêle des éléments de culture religieuse ordinaire et des velléités occultes, le risque est grand de surdéterminer la part cryptographique de ces grimoires, leur supposé secret. Du point de vue de l'herméneutique, le danger de confisquer la parole de l'auteur, s'il en est une audible, et de projeter nos fantasmes est toujours grand.

5 L'un des grands mérites de cette édition est justement de ne pas sombrer dans cet écueil et d'éviter tant que faire se peut de reconduire certains tropes du monde de l'art brut et de ses interprètes et zélateurs. Là, le mythe voire la mystification de l'authenticité et de la création pure évince trop souvent toute étude rigoureuse de l'histoire, de l'usage ou de la fonction de ce que Jean Dubuffet nommait les " ouvrages " des « auteurs » d'art brut. Comme le rappelle Marc Décimo, «les délires s'historicisent toujours» (p. 83). On pourrait ajouter qu'ils sont un redoutable outil d'analyse anthropologique et historique, doués d'un pouvoir heuristique non négligeable. La microstoria gagne à se frotter à ce qui, de près ou de loin, s'apparente à l'art brut, et vice-versa. À propos d'une tout autre période, Sylvain Piron a démontré avec force combien les enluminures hors normes du clerc Opicino de Canistris, mort à la cour papale d'Avignon vers 1353, permettaient, à force d'analyses scrupuleuses, de restituer les forces qui traversent les hommes et les informent à une période donnée, parfois au risque de l'effondrement psychique ${ }^{2}$. Si Pierre Richard n'est pas un lettré comme Opicino ou Georges Focus, il n'en reste pas moins traversé par des forces analogues qui agissent son ouvrage.

6 La mémoire propre au monde des femmes et des hommes du commun, souvent fragmentaire sinon passée sous silence, circule fréquemment via l'écriture ordinaire, celle-là même qui fut longtemps dédaignée par les sciences humaines et sociales mais informe sur la vie et les usages du passé et du présent. Par son caractère a priori exceptionnel sur la forme et sur le fond, l'ouvrage de Pierre Richard échappe quelque peu à ce registre. Mais c'est paradoxalement cet écart, cette singularité qui renvoient à 
la norme et permettent de mieux la circonscrire, la décrire et la comprendre. La norme de Pierre Richard, c'est celle de la campagne lorraine soumise aux vicissitudes du temps, d'un empire l'autre, écartelée entre deux langues au risque de la dissociation. Une Lorraine de la guerre où la figure de Bonaparte - sans grande surprise présente dans le second album - fait nombre d'incursions armées. Une Lorraine où la religion bien sûr est omniprésente au lendemain du grand bouleversement qu'impulse la Révolution, s'entremêlant à des savoirs populaires où pratiques superstitieuses et magiques participent du quotidien et conjurent les angoisses qu'il génère. C'est aussi la Lorraine des Wettersegen (enseignes bénies contre les intempéries) et des estampes religieuses colportées, dont Pierre Richard donne à voir une image comme reflétée par un miroir déformant. Celle de la messe où les fidèles psalmodient en chœur à certains moments de l'oraison dans un latin qu'ils ne comprennent pas ainsi que celle des ritournelles enfantines, mélange d'allitérations et d'homophonies dont Pierre Richard fait son miel, rendant le mot à son oralité stricte, là où le sens éclate sous une forme polyphonique.

7 On regrette un peu que certaines contributions cèdent parfois trop rapidement à une approche comparatiste de l'histoire de l'art fondée sur des analogies formelles et thématiques peu fécondes. La "relation aux modèles » (p. 189) est bien justement l'une des choses dont l'art brut pensé par Dubuffet engage à se méfier. Convoquer Raban Maur ou Granville pour qualifier l'« œuvre» de Pierre Richard d'un point de vue strictement iconographique, sous couvert de similitude du point de vue de la forme, est peu productif. Et l'on est en droit de soupçonner que ce type d'opération participe moins d'un travail heuristique que d'un effort tactique d'artification dont les "grimoires ", par leur qualité intrinsèque, peuvent se passer. Plus judicieuse serait une analyse comparée des mêmes termes sans reconduire la distinction entre culture populaire et culture savante - les apparentés à l'art brut permettent justement de déjouer cette séparation -, tout en restant soucieux de l'historicité et des contextes, pour mieux saisir ce qui, ici et là, relève de la possibilité d'élaborer à nouveaux frais des analyses comparatistes revisitant la tradition de la Gestaltung et l'héritage de Hans Prinzhorn. Soit à partir de l'art brut, penser l'art ${ }^{3}$.

\section{NOTES}

1. Sur ce point, voir le récent catalogue de l'exposition "Scrivere disegnando", Écrire en dessinant: quand la langue cherche son autre, Andrea Bellini et Sarah Lombardi (dir.), Genève, Centre d'art contemporain/skira, 2020.

2. Sylvain Piron, Dialectique du monstre : enquête sur Opicino de Canistris, Bruxelles, Zones sensibles, 2015.

3. Jean Starobinski, "Préface", in Hans Prinzhorn, Expressions de la folie: dessins, peintures, sculptures d'asile [1922], Paris, Gallimard, 1984 : XIV ; Céline Delavaux, L'Art brut, un fantasme de peintre, Paris, Flammarion, 2018 [2010]. 


\section{AUTEURS}

\section{BAPTISTE BRUN}

brunbaptiste[at]yahoo.fr 